\title{
Effective Look-up Techniques to Approach a Monolingual Dictionary
}

\author{
Nauman Al Amin Ali El Sayed \\ Assistant Professor - English Department \\ Faculty of Arts - Khartoum University \\ on Secondment to Shaqra University - KSA 11911 \\ Ahmed Gumaa Siddiek (Corresponding Author) \\ Head of English Department \\ College of Science \& Humanities - Dawadami - P.O.Box 18 \\ Shaqra University - KSA 11911 \\ E-mail: aahmedgumaa@yahoo.com
}

Received: 23-04-2013

doi:10.7575/aiac.ijalel.v.2n.4p.218
Accepted: 29-05-2013

Published: 01-07-2013

\begin{abstract}
A dictionary is (a) learning tool that can help the language learner in acquiring great knowledge of and about a foreign language. Almost all language learners buy or at least possess, at one time, a monolingual or bilingual dictionary, to which the learner may refer to look up the meaning of words. Unfortunately, using dictionary to look up the meaning of words seems to be the most important service, which a dictionary is expected to provide to language learners. In fact, a dictionary provides much data about language to its readers such as telling them about: the word spelling, phonology, phonetics, etymology, stylistics and definitions among other aspects. This paper sheds light on how the dictionary can teach its readers with special focus on monolingual dictionary. Hence, the discussion of this paper will centre on how dictionaries can teach students rather than on how students can learn from them.
\end{abstract}

Keywords: monolingual dictionary, learning strategies, language acquisition, lexicography

\section{Overview}

Language learning requires a number of techniques to enable the learners master the target languages. These techniques are technically known as "study skills". It is our duty as language instructors to interact with language learners effectively to engage them on right learning process. Good learning habits are necessary to enhance language learning from the beginning. Learning a language is a cultivation of habits and adoption of specific strategies to attain the mastery of the language. According to Oxford (1990 b), foreign or second language (L2) learning strategies are specific actions, behaviors, steps, or techniques students use - often consciously - to improve their progress in apprehending, internalizing, and using the L2. So Strategies are the tools for active, self-directed involvement needed for developing L2 communicative ability (O'Malley \& Chamot, 1990). These learning strategies are essential study techniques which are needed to help learners navigate their dictionaries when they need to know the meaning of a word or other features explained in the entries of the dictionary.

While dictionaries have been the focus of a considerable body of research (e.g. Atkins, 1985; Bejoint, 1994; Stein,1991, 1999, 2002; Battenberg, 1992, 1998; Hartmann, 1989, 1991, 2005, and Wright, 2001), no sufficient interest is shown in users, and despite the previous research on the area of dictionaries, there is still a gap that this study attempts to fill. Hence, the dictionary user has singularly been left out of the picture, ignored or overlooked. But one is tempted, naturally, to agree with Stein (2002) that no account of dictionaries is complete without "noting the user, his needs, his expectations, and his prejudices ". Much of the investigation has focused on the suitability of information found in dictionary entries. Hence, the discussion -here- centres on how dictionaries can teach students rather than on how students can learn from them. In the same vein, Hartmann (1991) writes: Ultimately, all dictionaries are motivated by and judged against the lexical needs of the language users whom they serve. Thus, a gap exists and more research concerning dictionary users and such matters as utilization of dictionary components in real language tasks is needed for determining the real needs of real people in the contexts of communication conflict and deficit.

It is no wonder, then, that most learners are unable to use the inexhaustible capacities that EFL dictionaries hold ready for them. But it is precisely the learners according to whose norms the success or failure of the EFL dictionary is to be determined, in line with Dr. Johnson's (1747) famous statement, (quoted in Hartmann), (1991):

The value of a work must be estimated by its use. It is not enough that a dictionary delights the critic, unless at the same time it instructs the learner. 
Dictionaries, however, do not only instruct and enlighten the students (Scholfield, 2001) despite their ubiquity and the wealth of information they contain in terms of phonology, morphology, grammar and semantics, and so students think of them as just another book to help them look up words, while the underuse of dictionary might be attributable to lack of instruction in the area of lexicography, its omission from the syllabus, and lack of conviction on the part of (oldfashioned) teachers to teach the myriad aspects of dictionaries. The consequences are observable - student's oral and written production is often characterized by inappropriate word and phonological choice, lack of grammatical, lexical and semantic precision and social constraints on discourse.

\subsection{Rationale}

The problem of this research stems from the fact that teachers and students are unaware and/or have little knowledge of the importance of using dictionaries in their classes. Even a considerable number of teachers and dictionary users have little knowledge about the huge wealth of knowledge which the dictionary can provide to them. Most learners have the habits of quickly looking-up only one aspect of the dictionary entry of a word-mostly the meaning- while there are more than ten components which a good dictionary can provide them when it is - fluently consulted. This paper is trying to shed light on some details about these components of dictionary entry which everyone should know when he seeks the advice of his monolingual or bilingual dictionary.

\subsection{Significance of the Research}

This research is of great importance as it will shed light on different linguist components about dictionary entries. The awareness with these components will help both: teachers and learners to enhance the language teaching and learning. Moreover, the findings of this survey will also be of great and practical use for syllabus designers, as the survey will focus on this point by advising them to include dictionary skills in their syllabus and textbooks. One more point is that the results are going to be of great interest to lexicographers as the survey will focus on the most important features that a good dictionary should contain.

\subsection{Methodology of the Study}

To realize the objectives of this study a critical and a thorough survey of reading was carried out to collect the data from different authentic references about the topic. So the researchers have consulted many authorities in the field to collect this information. No further research instrument was needed as the focus was mainly on collecting details already scattered in books and rearrange them in objective manner.

\section{What is a dictionary?}

These are some definitions of the word "dictionary" directly extracted from the net. A dictionary is a book of words of a particular language and their accepted definitions, origins, parts of speech, pronunciation, spelling and in some cases a sample of their use. Depending on the age and target audience, it may also contain cultural slang and/or other nontraditional words as well. See (http://wiki.answers.com/Q/What_is_a_dictionary.)

Another definition for dictionary is "a book that lists the words of a language in alphabetical order and gives their meaning.

See (http://www.businessdictionary.com/definition/reference.html).

A dictionary is seen as a "reference source of words in a language or discipline, arranged alphabetically. In addition to defining the words, larger dictionaries also provide information on the spellings, pronunciation, word origins (etymology), functions, and different forms of the word. See also thesaurus.

(http://www.businessdictionary.com/definition/dictionary.)

But a comprehensive definition of the dictionary is suggested by Zgusta (1971: 197) in his authoritative text on lexicography:

"A dictionary is a systematically arranged list of socialized linguistic forms compiled from the speech habits of a given speech community and commented upon in such a way that the qualified reader understands the meaning of each separate form, and is informed of the relevant facts concerning the function of that form in its community ".

\subsection{Components of EFL Monolingual Dictionaries}

Entries differ in content and organisation from one EFL dictionary to another. Yet, certain standard components have been identified by Atkins (1985) as follows:

1 - Lexemes.

2- Spelling.

3- Indication of pronunciation.

4- Grammatical information (including parts of speech, morphological information and verb patterns).

5- Definition.

6- Illustrative examples.

7- Idioms.

8- Graphic illustrations.

9- Cross-reference.

10- Etymology.

11- Stylistic variations. 
The above eleven components will be considered in some details in the following section, as they are the backbone of any entry in an EFL monolingual dictionary. Theoretical discussion of these components will be reinforced by constant reference to the four established British EFL monolingual dictionaries: OALD, LDOCE, CULD and CCELD.

\subsection{Lexemes}

Dictionaries are essentially lists of base or citation forms printed in bold type and provided with the semantic and other information written against them. Jackson (1988:7) gives the example of these theoretical constructs as "girl" "girl's" "girls" "girls';" "tiny" "tinier" "tiniest" and "sew", "sewing", "sewn", "sewed". These words are the same albeit different. They are different orthographic and phonological words; they have distinct spelling and pronunciation as they are different words used in different grammatical contexts. But when essential meaning is concerned, they can be regarded as lexemes which are the realisations of the same theoretical entity having the same status as phonemes and morphemes. Lexemes are independent units and the above three lists of words are not cases of polysemy. The dictionary does not enter the different senses of these words; they are rather cases of variant forms dictated by grammatical function. They are not given the status of full headwords and they include compounds, prefixes and suffixes of the headword (ibid). Equally, a dictionary includes polysemous words under the same lexemes as in the cases of:

They grow a lot of apples in the country.

He has grown up so fast.

Where there is sufficient continuity of meaning to justify the inclusion the second sentence under the main lexeme "take", "take up" will normally be a run-on entry. However, there are examples of homonymous words that have the same form but different meanings (Palmer, 1995), while polysemous words are grouped together under the same entry e.g. human "foot" and "foot" of the mountain. Homonyms merit separate entries. According to Battenburg (1992: 51) homonymy is thought to begin when native speakers are unable to conceive how different meanings of a lexeme are related, e.g. "pupil" in a school and "pupil" of the eye; "spring" as a season, "spring" of the clock, and "spring" of water. But there are dubious cases pointed out by Zgusta (1971:40): a speaker depending upon his background may analyse the English word "minister", meaning (1) state dignitary, and (2) clergyman as either polysemous or homonymous. The distinction between polysemy and homonymy is particularly important in an EFL dictionary where a balance between pedagogical inclusiveness, space-saving and cost-effectiveness must be made (Stein, 2002:11). Maximizing homonymy would create more entries beyond the scope of a pedagogical dictionary, whereas maximizing polysemy would make lengthy and difficult entries for the learner. Hence a middle course has to be adopted that takes into consideration the range of the entries to be covered (decided best by corpus - based frequency counts), user- friendliness, ease of access and economic considerations to create a dictionary that strikes the best measure between homonymy and polysemy.

\subsection{Spelling}

All the material in an EFL dictionary is of no value if the users are unable to locate the headword. The problem is, of course, how to find the spelling (s) of the lexical items if one has no idea where to begin the search. Thus, the first task of the dictionary editor is to decide on the spelling of the entry words (Hulbert, 1992). The terms "spelling" and "orthography" commonly refer to the sequence of letters within words (Battenburg, 1992:29). .

Usually a modem dictionary affords no difficulty as usage has fixed a single spelling. Yet there are variant forms such as "medieval" and "mediaeval", "fetal" and "foetal", "inquire" and "enquire", "judgement" and "judgment". (Jackson, 1988) adds that despite these distinctions, spelling is usually fixed for a particular national variety of English (British English, in our case) given as the main entry. For Landau (1983:78) the entry indicates the normal or preferred spelling, the usual printed form of the lexical unit (whether capitalised or not, whether considered foreign (and italicised) or naturalised.

A final type of information in the main entry is syllabification. Illson (1985), states that British and American English differ in handling syllabification; the former uses phonological criteria (struc/ture), whereas the latter uses morphological and etymological criteria (struct/ure) though the American tradition is more adopted as it is more suited to EFL learners. So, EFL dictionaries list both variant spelling and syllabification, though Battenburg (1992) warns against including too many of these and suggests using the saved space to include anticipated erroneous spelling in the main body of the dictionary and to be cross-referenced in the appendices.

It is the reference in Western lexicography to use the infinitive form for the main entry (Jackson, 1988). This is important in the EFL dictionaries, as students may not know the canonical foffi1, especially in the cases of inflection and derivation which may be markedly different from the canonical form, e.g. "is" and "be", "taught", "mice", "belief', "heavily", "well", etc. The above lexemes will be included under the main entry in the belief that adverbs, adjectives, and even nouns may be run-on entries and that the knowledge of the main foffil will signal the knowledge of the derived form, e.g. "teacher" is one who "teaches". Yet, this approach has its dangers since derivatives may include senses peculiar to themselves. Landau (1989:78) takes the example of "obviously" which does not mean "in an obvious manner" and the interpretation of "oddly" as "in an odd manner" is both misleading and ambiguous. The researcher can stress this point by a more recent example of "terrorism" which is listed in traditional EFL dictionaries under "terror", thus disregarding the great significance and the connotation the word has acquired after the 11 of September attacks on the U.S.A. that has made the teffil a household name. It will be more fruitful to assign the word to a main entry, but none of the four dictionaries do. 


\subsection{Pronunciation}

A good starting point for this section is the comment by Hulbert (1992) that EFL dictionaries are less satisfactory in pronunciation than in spelling, meaning, and etymology. The reason is simple - the recording of spoken language is difficult to acquire, difficult to transcribe accurately and unambiguously, and difficult to represent understandably in dictionary transcription. Moreover, Landau (1989:94) mentions other major problems in pronunciation parallel to those of establishing the written canonical form such as deciding which pronunciation will be' regarded as preferred considering the great number of dialects in a given language. In the present research the scope is narrow, namely British English and its recording in British EFL dictionaries. But even here, the British lexicographer should first resolve a number of questions such as what type of pronunciation system is to be used, how narrow or broad should the transcription be, how many variant pronunciations will be included and, finally, which British dialect is to be recorded.

A partial solution to the above problems has been made with the adoption of the Received Pronunciation of Southern England based on the careful speech of educated speakers of public schools and the BBC. It is a variety which is spoken by a small number of people yet understood by the greatest number of the public and was associated with prestige and symbolic power (Bourdieu, 1992). Another side of the question is resolved by adoption of the International Phonetic Alphabet, out of many competing systems, in OALD and LDOCE following the tradition of Daniel Jones, famous. "Everyman's Pronunciation Dictionary" (1975) and the later excellent text by his student A.C. Gimson "An Introduction to the Pronunciation of English" (1989). This system is particularly good for English language with its long history of foreign influence and the great number of loanwords. The well-known difficulty in representing pronunciation is that letters of the alphabet represent more than one sound (Landau, 1989). There is no simple symbol - sound correspondence, that is, the letter of the alphabet does not represent the same sound all the time, nor does a specific sound find its representation in one letter (Celeca - Murcia, 2005). She (ibid) cites the example of the letter (c) which has different pronunciations in "cat", "city", "ocean", "cello" and two sounds in "success", and $|\mathbf{s}|$ which has different spelling representations, e.g. s, sm c, and sc. Also "a" is pronounced differently in "woman", |Ә|, "man", | |,"heart" |a:|, and "place" |e1|.

The best way out is by substitution of the notion of phoneme instead of letters of vowels and consonants. The resultant 44 phonemes can be used to cover up to two-hundred spellings and include all the sound realizations in the spoken language of British people. Phonemes are theoretical constructs, composites of similar but variously articulated speech sounds appearing in contrastive distribution and distinguishing English words such as "sin" "sir" "sip" "site" "sill" etc (Lyons 2001). The resultant 44 distinctions follow the consonants (sounds with obstruction of airflow) and vowels (sounds with a continuous vibration of vocal cords), where there is no contact between articulators. The phonetic transcription is normally enclosed between two broad slashes but in cases of more than one option, the choices are listed.

However, the duties of dictionaries do not stop at segmental (phonemic) features but extend to suprasegmental ones such as syllable and stress, increasingly perceived as important to comprehensible pronunciation as the phonemes themselves. Basic to this insight is the notion of "syllable" defined by Celce -Murcia (2005) as segmentation of sound units which is indicated in the chest-pulse theory e.g. the little puffs of airstreams leaving the tongue as in "Atlantic" composed of three syllables. What is more important is, of course, the emphasis some syllables receive at the expense of others and referred to as "stress". Stressed syllables, according to Lyons (2001), are those syllables that are longer, louder, higher in pitch, and involving greater outburst of energy and increase in muscular movement and respiratory activity. Three degrees of stress are recognized in EFL dictionaries: primary (main), secondary, and unstressed. To indicate strongly stressed syllables, OALD and LDOCE use the convention of a superscript accent mark (') placed immediately before the stressed syllable as in "under".

\subsection{Grammatical Information}

This is a particularly important part of entry in the EFL dictionary. It can be divided into the following parts:

\subsubsection{Morphological Information}

A general -purpose EFL dictionary describes the vocabulary stock of a language. This consists of primary and secondary elements. Primary elements, according to Stein (1992), are linguistic signs in the Saussurean sense of the term which cannot be analyzed further into smaller linguistic signs but which serves as a basis for the secondary items. They typically occur as either free morphemes, e.g. "bake", "bed", "power", "river", etc, or bound morphemes, e.g. combinations of primary elements. Examples in English include "baker", "baking", "bedding", etc. Bound morphemes are generally regarded as being either inflectional or derivational in function (Stein, 2002). The former is part of lexicology, while the latter belongs to the field of word-formation. Below, treatment of derivational morphology in a dictionary is dealt with first:

Derivation (word-formation) includes the linguistic elements used in the processes of word-formation and can include suffixes and prefixes. Because of the great number of these in English there is an issue of which item to include and where they figure as main or run-on entries. As a matter of fact, for Battenburg (1992), affixes are usually expected to be given a relatively superficial treatment in a learners' dictionary and to be given run-on status within the lexemes. On the other hand, Bolinger (1985) complains that affixes are usually given extremely brief definitions and' the treatment is unsatisfactory which in cases can be misleading as in the example of "arch" in Bolinger (ibid) taken from LDOCE:

Arch - prefix (1) chief, superior (archbishop) archdiocese, arcduke), (2) preeminent, esp extremely bad. (archfiend)... 
This definition would not prevent the user from coining such words as archcivilservant, archofficer, and archteacher for sense (2). What is missing is the mention of collocationals (selectional restrictions with respect to semantic classes of nouns) that can be combined with the prefix "arch". Also for Stein (2002:62), another problem of these dictionaries is that the synchronic principle is not recognized. So there is "a problem with the productive aspects of affixes: Stein (ibid) cites OALD- ab- (pref:) (1) far away: e. g. "absent", "abduct". This makes it impossible for learners to generate new "ab" derivatives. Another problem with these small constructions is that while spelling variants such as "haemoid" and "herno" are given, the indication of pronunciation is not a universal principle, and restrictive labels are not as consistently applied as to other lexical items. As for the unnecessary practice of the inclusion of as many derivative morphemes as possible, Landau (1989:78) argues that latent words such as "sluggishness", and "identicalness" are included into a dictionary even though there is no record that such terms have ever been used. Second, and more importantly, the dictionary often fails to deal with the semantic differences between these derived forms and headwords. To illustrate, Landau (ibid) points out that the words "strongly" and "oddly" are commonly included as derived forms and are supposed to mean "in a ... manner". The problem with this is that these lexical items are not being defined. In addition it is used with all of the senses of the word entry. Another difficulty raised by Battenburg (1992:69) $\mathrm{s}$ that it is not clear how lexicographers decide the lexical items that deserve individual main entries and which ones can be listed as derivatives. Typically, the more basic grammatical forms are recorded as the headwords. However, it is erroneous to think that these forms are the more basic grammatically: Battenburg (ibid) records the inconsistency between EFL dictionaries on the arrangement of such items. For example LDOCE includes both "hypocrisy" and "hypocrite" as separate main entries while "hypocritical" is recorded under the latter. The OALD in contrast lists "hypocrisy" as the headword and includes the other two items as run-on entries.

A dictionary has to distinguish between polysemy and homonymy. Homonyms need a separate entry in the dictionary e.g. "ear" (organ of hearing) and "ear" (part of cereal plant e.g. corn) are not related in meaning etymologically, so they constitute two separate headwords. On the other hand, "foot" (projection of a leg) and "foot" (bottom part of a page, mountain etc.) are plysemous, the second representing an extension of a meaning of the first. Therefore these are entered as variant meanings (senses) of the same headword.

\subsubsection{Parts of Speech}

Stein (2002) argues that modern EFL dictionaries became more "grammaticalised". There are traditionally nine parts of speech: verbs, nouns, adverbs, adjectives, pronouns, conjunctions, prepositions, interjections, and articles. However, lexicographers are to blame for their ready acceptance of the Latin terminology, for a lexical item can be a member of several parts of speech, such as the word "over" where in LDOCE it is a preposition as in the sentence: "the lamp hung over the wall", or an adverb like in" "I fell over", or an adjective liken in" "I'm sorry the party is over", or even a noun like in: "cricket over", referring to a set of six or eight balls in the same direction for one bowler.

EFL dictionaries also provide morphological information about a word, for example whether it is a noun, whether it is a countable noun or a mass noun, etc, in short, as Battenburg (1992) argues that isolated parts of speech help learners but minimally. The morphological and semantic subdivision of this material should receive more treatment as well as the syntactic patterns related to some of them as is clear in the topic of the net section. EFL dictionaries such as OALD and LDOE commonly use separate entries for each part of speech, while CCELD and CULD, in contrast, often deal with all parts of speech in one entry. Moreover, it can be claimed that traditional grammatical terms are circular, that they depend upon a mixture of morphological, syntactic and semantic criteria that do not coincide in particular instances and that they are inapplicable to languages whose grammatical structures differ significantly from those of classical IndoEuropean languages (Lyons, 1977:422).

\subsubsection{Syntactic Patterns}

Grammar information is necessary for an EFL learner, so EFL dictionaries provide considerable treatment of it. Information about a verb transitivity or intransitivity is provided as is explained by Hornby (1975) in his "A Guide to Patterns and Usages in English". For Nesi (2001), however even the advanced students have difficulty deciphering these patterns and cocks. In the later editions of OALD (e.g. that of 1995) thirty-two verb patterns are used in the text. Longman Dictionary $(1978,1995) \ldots$

Longman Dictionary $(1978,1995)$ extended Hornby's syntactic patterns to other parts of speech (Hornby's system focuses on the verb as the centre of the sentence). LDOCE coded noun, and adjective and adverb complementation as well, thus developing the system a step further. Grammatical patterns are noted and illustrated somewhat mnemonically in entries, and according to Stein (2004), four major types of codes are used: .

1- Letter codes, like (1) (T) (C) (V).

2- Prepositions or adverbs which may follow lexical items like (to) or (with).

3- Verb patterns such as (+ to - $\mathrm{v}$ ) or ( $\mathrm{v}$-ing).

4- Other restrictions concerning the usage of a word like (such - sing.), (usu. in negative), or (not in progressive form) (F 39).

Finally, CELED lists parts of speech and syntactic patterns in an "extra column" located to the right of the dictionary entry. Five major word classes are dealt with (Battenbrug, 1992): nouns, adjectives, verbs, adverbs and phrasal verbs. 143 common patterns are illustrated in the dictionary and explained in the appendices. Along with the grammatical labels, symbols such as commas, colons, slashes, and addition signs are used to show relation,. For example, V: of + at 
represents an intransitive. verb which is often followed by a prepositional phrase beginning with "at" (e.g. we are aiming at higher production levels).

It is clear from the above differences in the nature and quantity of patterns that little consensus exists over how much coded information should be incorporated into dictionary entry. While fruits of patterns are clear, writers have sought ways by which to keep codes, symbols and abbreviations to the minimum by using mnemonic code and saving the task of memorization or by improving design and providing these codes, together with illustration example designs (Battenburg, 1992).

\subsection{Definition}

No other part of the dictionary entry has received more attention by lexicographers than the semantic component. Indeed Kipfer (1984: 11) writes: "Definitions are the meat of the lexicographical profession. Practically, no other component requires as much space and demands more labour and affects the potential success or failure of the dictionary text than the quality of its definitions". This point leads Zgusta (1971:2) to claim that "practically all decisions of the lexicographer are in direct or indirect relation to the way in which he deals with lexical meaning". Because of the importance of definition, it will have more sections given to it here than any other entry component.

\section{2:6.1 Characteristics of Lexicographical Definition}

Setting out to define a lexical item for language learners is a challenging task. Unlike the semanticist whose sole interest is in the, formal and philosophical nature of meaning, the EFL lexicographer starts from the assumption that their users cannot pair a particular word with a particular experience of the world. They therefore, describe the meaning of words or sometimes describe the referent and its functioning in order to help their users grasp the referents. The lexicographers' task is to provide definitions which are accurate descriptions of inherent semantic properties of lexemes based on best available evidence. Moreover, the meaning of a lexeme involves not just what it denotes intrinsically but also its relation with other lexical items of similar or opposite meaning in the same lexical field that regularly co-occurs with it (Jackson, 1988:42). But providing all these conditions in a definition is by no means easy, as stressed by Stein (2002: 116):

"To match a lexical unit with a single phrase whose content is appropriate semantically, and whose form is appropriate syntactically is perhaps the most demanding task in lexicography. It is not surprising that some definitions fail to achieve their aims. What is surprising is that a lexicographical definition ever succeeds".

Let us discuss some of the implications involved. An EFL dictionary has an obligation, on one hand, to supply the individual senses of a lexeme and a broad and general definition applicable in many contexts, on the other. Moreover, as Underhill (1989) points out, dictionaries have an obligation to handle not only denotation meaning but also additional or connotation ones to be inclusive. If the meaning of a lexeme is a sum of its linguistic uses that a speech community assigns to it, then a dictionary has to consider all such linguistic experience. Battenburg (1992:48) emphasizes this by the example of the sentence: "School started to day and it was a zoo". The student might consult OALD to find the standard denotative definition of "zoo" as "place (e.g. garden, park, etc.) where living (especially wild) animals are kept for exhibition, study and breeding". What the student needs is the fact that "zoo" has a connotative meaning of a disorganized place with noisy and unruly people. Unfortunately, this sense is not found in the dictionary. However, it should be stressed that EFL dictionaries deal with generalized meanings and are not the place where what Bosch (1988:67) call "the contextual notion" of words in concrete terms.

The lexicographer has other duties, too, such as making some arbitrary decisions about ordering polysemous words. Although lexicographers may organize meanings by panchronic frequency (Battenburg, 1992:53), more common practices dictate ordering by historical appearance or importance. According to Whitcut (1985:76) a historically ordered dictionary tells the reader, for instance, by the way it is ordered which is the oldest sense and hence puts the meaning of "fowl" as "any kind of bird" first before the later sense of a "domestic hen". It is understandable that historical ordering has little place for the more utilitarian EFL dictionaries which prefer using the importance criterion. In this type senses are listed in decreasing importance or usefulness. More recently, the importance criterion has been determined more accurately through the frequency of an item measured in an authentic corpus of a language as shown in the COBUILD project $(1987,1995)$ which concentrates on the most basic 15,000 items in English in common use.

EFL lexicography has evolved user-friendly principles over the years to render their definitions accessible and easy in reference. The defining styles of OALD, LDOCE CULD and CCELD have adhered to principles stated by Zgusta (1971) including the conditions that all words within a definition should not contain words more difficult to understand than the word defined, that the defined word may not be used in redefinition, nor may the combinations of the defined word unless they are separately defined. Landau (1984:124) adds the necessity for avoidance of circularity i.e. defining two words in terms of each other e.g. "bobcat" as "lynx" and "lynx" as "bobcat". Finally, one common practice described by Stein (2002:90) is the condition that explanations provided after the headword should be given in syntactically related form as there should be grammatical equivalence between the headword and the definition, that is if the headword is a verb, e.g. fetch, the information provided in the definition should have the status of a verb, to go , and a noun phrase for a noun e.g. "man" as "adult human being". The theoretical principle behind this is that a definition should be a substitute for the lemma. 


\subsubsection{Methods of Definition}

Essentially, lexicographical definition is identified through comparison. It is a semantic description of words which should enable the dictionary user to identify the meaning properties of lexemes. Since words can share parts, it is crucial to point out the differentiating factors, and these discriminations, according to Stein (2002:42), can be linguistic and non-linguistic. Writing definitions is not a simple straightforward task with a set of agreed-upon procedures (Jackson, 1988: 134), and EFL dictionaries have evolved policies different from their native language counterparts. These defining methods can be Formal i.e. describing the inherent properties of a lexeme, or lexical that is defined through the relation of a lexeme to other lexemes. We will start with the first method.

Formal methods are divided into four kinds. The first is the analytical method which discriminates species by listing both the genus and the differentiate. Thus a large class is given and then an individual member is distinguished form other members. An example of this method is the definition of "daffodil" in OALD:

Daffodil ------- (any various plants with flowers that have large typically yellow corona elongated into a trumpet shape). The analytical method is often useful because the semantic field is clearly indicated and then the differentiations characteristics are suggested, commonly in the form of adjective or adjective clauses. The synthetic method, in contrast, relates the object or concept being identified with another object or concept. Thus, while the analytical method indicates the thing meant by showing it as a whole of parts, the synthetic method shows it as part of a whole. As example is green defined as: (green ----- a colour whose hue resembles that of growing fresh grass or emeralds and lies between yellow and blue in spectrum). "Green" is put into relation with other entities and shown as part of a whole (spectrum).

The third method is typifying, where the defining focus is on what is typical about the referent of the lexeme being defined, as in this example for "|hag fish" from LDOCE: (hagfish ------ any of several marine vertebrates that are related to the lampreys, resemble eels and feed on fishes by boring into their bodies).

Finally, there is the rule-giving method, which is often used for function words such as conjunctions, prepositions, pronouns, demonstratives, etc. Thus, words like "who" might not be defined actually. Instead, rules for their use are given. For instance, (CELD) illustrates the most common meaning of the preposition "to" with: you use "to II when indicating the direction that someone or something is moving towards or pointing at. The definition consists of rules expressing how the lexeme being defined is used, for what purpose and in what context.

Lexical relations are much used in definitions because senses for many lexemes are not easy to express. The lexicographer is forced to use sense relations, or some form of paraphrase. For example there is synonymy as in "profusion": abundance "cardinal": chief, important, "garb": clothing, "daft" : foolish, etc. Here the lexical item is defined by another word that the user is more apt t6 know. EFL dictionaries list synonyms as part of whole of the definition or after the definition. But for Battenburg (1992):47) synonyms offered without meaning discriminations is of little value and that students need guidance in distinguishing one from another. Less use is made of antonyrny as in "deceased": not alive, "unkempt": not tidy, "bondage": "lack of freedom", Finally, there is the use of hyponyrny as when "salmon" is defined by relating it to the superordinate "fish" or when a definition of "linguistics" is followed by a mention of its branches such as phonology, phonetics, semantics, etc.

\subsubsection{Illustrative Examples}

Illustrative examples, defined as sentences showing the uses of a lexeme in an actual context, are generally regarded as an extremely positive and useful feature of EFL dictionary and not a mere addition. For example, Drysdale (1987) claims that a well-constructed example can perform a wide range of functions such as distinguishing meanings, illustrating grammatical patterns and showing typical collocations, degree of formality, and designative meaning. Cowie (1989) also justifies examples in learners' dictionaries on the grounds that they help in the decoding process (2010:2) by clarifying meaning and distinguishing between related meanings, and in the encoding process by indicating grammatical patterns, acceptable collocations and native stylistic norms. Others like Stein (2002: 17) use a comparison to show their importance.

\section{"Like a picture, an example can be worth a thousand words of definitions. Examples can supplement and extend the definition, often with great economy of means. Furthermore, in definitions lacking examples, it is often more difficult for a user to bring to bear his or her knowledge of a word in context to help clarify meanings".}

It now seems that the value of examples can hardly be doubted but one issue arises concerning their quality, as some examples are better than others. Scholfield (1990) gives the illustrative example for "black sheep" appearing in two EFL dictionaries, one from CULD: My brother has always been the black sheep of the family because he has been to prison several times, as opposed to LDOCE : the black sheep of the family. Scholfield (ibid) claims that EFL students would be better served with the former. Although both examples indicate that the term "black sheep" is often used in the context of a family, only the CULD with its reference to prison indicates that the phrase "black sheep" often describes one who brings shame upon members of a family. It could be suggested that the fluctuating quality of examples above is due to the fact that they are both made up by writers of these two rather traditional dictionaries. However, with the rise of recent dictionaries like CCELD, a practice was adopted of quoting from written and oral texts. Consequently a debate has started over the merits and demerits of the two methods. The leader of the CCELD team, Sinclair (1989: 79) writes the following in support of the use of quoted materials: 
"There is something self-contradictory about the widespread custom of made-up examples, a sort of misleading game the lexicographer plays. Examples are of great value if they are attestations, where the lexicographer cites evidence which can be compared with statement, about the language. But when examples are concocted by some lexicographer, they have no value at all".

This artificiality can be supported by the examples in the entry of the 2006 edition of OALD for the word "tentative": make a tentative suggestion, proposal, plan, etc. reach a tentative conclusion. Such a sentence, quoted from exclusively written material, is artificial for Hartmann (1992) because the editing process used in writing can be removed from common everyday language. Yet, Battenburg (1992:64) believes that there are advantages in using illustrative sentences constructed by lexicographers, as such examples are often easier for the dictionary user to understand because they have been tailored to fit his needs. From the researcher's study of the four major EFL dictionaries he has noted the increasing tendency towards using examples quoted from a corpus as advertised on the cover of these dictionaries. This fact testified to the increasing computerization of English dictionaries, EFL dictionaries included.

\subsubsection{Graphic Illustrations}

Graphic illustrations in EFL dictionaries are an area to which little attention has been paid. Collinson (1992:20) notes:

"One very surprising aspect of EFL dictionaries is their general omission to make use of the powerful aid of illustrations when tackling the problem of interpreting words clearly and accurately. Illustration has always been an important feature of books, whether printed or in manuscript, but a very small proportion of dictionaries have been illustrated, even with thumbnail or marginal sketches".

The main objections to using graphic illustrations are the cost and the space required as well as editorial uncertainty as to the value of pictures, diagrams, charts, tables and drawings (Battenberg, 1992: 121). But the rationale behind graphic illustration is tied up with the very idea of monolingual dictionaries which, unlike bilinguals where exact equivalents are provided, have to start from the assumption that their users cannot pair a particular word with a particular experience in the world (Stein, 2002: 126). They therefore describe the meanings of words, and their functioning to help users grasp the referent. For Hupka (1995) the problem is more evident in natural kinds where monolingual dictionaries use scientific terms which are accurate but difficult to understand, e.g. carnation is "a cultivated variety of clove pink, with variously coloured showy flowers", The problems of definitions are complicated even more in EFL lexicography where descriptions have to be couched in simple language. Hence, according to Stein (2002: 126), pictorial illustrations might be a welcome bridge between some classes of words and referents, representing language usually, replacing verbal definitions by visual identifications, ensuring quick transformation of information and reinforcing learning through concrete representation.

Graphic illustrations can also take forms other than pictures. Hupka (1995) notes that tables can be useful in lexicography because a variety of concepts and relationships may be illustrated: contrast sets (e.g. dead); taxonomies (e.g. square, rectangle, parallelhram, quadrilateral); patrimonies (e.g. fingernail, finger, hand); paradigms (e.g. adult, young, infant); cycles (e.g. morning, afternoon, evening, night); chains (e.g. generals, officers, field officer, company officer); networks (e.g. parent, child); and frames (e.g. buy, sell, spend).

Stein (2002) studied graphic illustrations with particular reference to their employment in two EFL dictionaries that interest us in this research i.e. OALD and LDOCE. Between them, the two dictionaries include over 1,000 illustrations. By studying them carefully, Stein (2002: 127) could distinguish between four main types:

1- Illustrations showing common animals, objects, plants, etc.

2- Illustrations showing things that are not easily explained in words such as shapes, complex actions, or small differences between words which are similar but not the same.

3- Illustrations depicting groups of related objects and explaining the differences between similar objects.

4- Illustrations showing the basic or physical meanings of words that are commonly used in an abstract or figurative way.

The first category includes common and exotic flora and fauna and household and work tools, etc. Stein (ibid) cites the example of the entry for the word "elephant" from the fourth edition (1992) of OALD. The boldface word elephant is the headword or lemma which is followed by a paraphrase of the meanings.

The picture of the elephant precedes the actual dictionary entry. This verbal support of the picture relates it to the lemma elephant and not to the previous dictionary entry. The second type can be shown by the use of pictures to show the subtle difference between cross-legged and leg-crossed from LDOCE or the verb to parry where the illustration gives the two phases of the action. The third kind refers to referents that are grouped together on grounds of physical appearance, functions, etc. in representative groups. Stein (ibid) cites the drawings for gloves from OALD and wasp and crouch from LDOCE:

\subsection{Cross - reference}

It is a practice in dictionaries whereby EFI students are referred to specific information so that they can locate related entries or consult explanatory material. Hence cross-referencing, if used properly, can increase the effectiveness of EFI dictionaries and prove a powerful learning tool. Battenburg (1992) analyses the cross - referencing conventions in the three main EFL dictionaries. OALD indicates cross - reference with the sign $\rightarrow$.In other dictionaries, more traditional 
words such as "see" and "compare" are used. The advantage of using traditional symbols, as in LDOCE, is that students are given a preview of the cross-referenced entry. Unlike OALD where the $\rightarrow$ symbol simply tells users to consult another entry, LDOCE uses "opposite" which shows antonyms, "compare" which shows similar meaning, while "see" directs readers to consult a usage note or language note. The more recent CCELD $(1987,1995)$ also employs "see" and "see also". In addition, to indicate semantic relationships, three symbols are used in the extra column to illustrate synonymy, antonymy, and superordinate $=, \pm$ respectively.

Lexicographers, however, increasingly argue that the range of cross-referenced items should be extended. To take an example, Whitcut (1996:120) believes that it would be useful to cross - reference malapropisms such as "affect" and "effect" as well as twins like "lie" versus "lay" and "sit" versus "set". For Whitcut (ibid), ideally, makers of learners' dictionaries are to anticipate the types of errors language learners may make -simply listing even detailed entries in alphabetical order is not sufficient; explanations must be incorporated in these texts which help users with common areas of difficulty which might include, according to Stein (2002), various combinatorial possibilities including common prefixes e.g. de -, non -, semi -and un -, and suffixes (e.g. - haemo,-phobia -phobia and -thon). This information should appear within the A-Z text.

\subsection{Etymology}

Etymology has had different meanings depending on when and where the term was used, yet today most would agree with Makiel (2000: 179) that this term:

\section{"Best applies to the objective elucidation of word origin -such information may range from a single word indicating a historical linguistic form to a lengthy paragraph tracing the origin of a word and its succeeding changes down through history".}

The rationale behind etymology is the widespread belief held by learned people that the best way to find out what a word means is to find out what it previously meant or what it originally meant (Landau, 1989:98). Though etymology is not normally included in EFL dictionaries, we will discuss it briefly. Etymological information normally includes the source language or language family, date or period of entry in English, semantic development and other English words derived from the base (Battenburg, 1992). It is widely believed to shed light on meanings of medical and technical words derived from. Latin or Greek but even this is made doubtful because words might diverge from their original meanings. While native English dictionaries normally contain brief etymologies, EFL dictionaries normally avoid them despite their fascination for most learners. Their apparent uselessness is exemplified by Battenburg (1992: 60) who claims that no EFL lexicographer would argue that EFL students need to know that the verb "follow" comes from the Anglo-Saxon "folgian" or "flagon", or that the adjective "rich" come from the Anglo-Saxon "rice" which is a cognate of the Latin "rex". The above view has long been held by EFL lexicographers but more moderate ideas are suggested by more modem writers like Ilson (1985) who declares that etymology is useful but has to be extended beyond its more deep scholarly traditional sense and be modernized to designate how a word, phrase, or meaning came into being. For him (ibid) etymology should account for four types of information:

1- Etyma and cognates, including borrowing and loan translations.

2- Morphological analysis of lexical units in tefll1s of their constituent structure, which might, for example, include inflammable as "inflame + able", not "in+flammable".

3- Morphological analysis of lexical units in terms of the processes of word-formation. Such an analysis might describe "brunch" as a blend of "breakfast" and "lunch" and "flu" as short for "influenza".

4- Analysis of lexical units in terms of cognitive procedures (e.g. metaphors, historical allusion) of their formation and development.

\section{Conclusions}

'Look-up' problems may be caused by learners' wrong habits. Of course, the commonest one is haste in looking up a dictionary, regarding it as a last resort to be used mechanically. Research by Tono (1989:18) equally found that learners have no patience with consulting dictionaries and tend to focus on material appearing at the beginning of the entry. Indeed this antipathy towards dictionaries could be so great that students eschew using them where they are needed most. For example, there are the "faux aims" like the French "actions" in the sense of "share" and German "Aktion" which a student might confuse because of interlingual judgment. Also, many EFL students systematically misinterpret dictionary entries (Nesi 1994), for two reasons:

\footnotetext{
"The dictionary user latches onto a part of the dictionary definition without really understanding how it relates to the word they are looking up. Also, the dictionary may be misleading from the user's point of view.
}

It is hoped that dictionary writers will improve dictionaries and that teachers will train their students to use their dictionaries effectively. 


\section{References}

Atkins, B. T.S. (ed.,). (1998). Using Dictionaries: studies of dictionary use by language learners and translators. Niemeyer: Tübingen.

Battenburg, John. (1992). English Monolingual Learners' Dictionaries: A User-Oriented Study. Lexicographica, Series Maior 39. Tübingen, Germany: Niemeyer Press, 1991

Bejoint, H. (1994). Tradition and Innovation in Modern English Dictionaries. Oxford: Oxford University Press.

Benoussan, M., Sim, D. and Weiss, R. (1984). The effect of dictionary usage on EFL test performance compared with student and teacher attitudes and expectations. Readings in a Foreign Language, 2, 262-276.

Bolinger, D. (1994). Defining the Indefinable. In Illson, R. (ed.) Dictionaries, Vocabulary, and Language Learning. Oxford: Oxford University Press.

Bosch, P. (1988). On representing lexical meaning. In Hullen (ed.,). Meaning and Lexicography. München: Lebende Sprache.

Bourdieu, J. (1991): Symbolic Power. Cambridge: The Polity Press

Celce -Murcia, M. (2005). Teaching Pronunciation. Cambridge University Press.

Collinson, R. (1992). A History of Foreign Language Dictionaries. London: Deutsch.

Cowie, A.P. and Howarth, P. (1996). Phraseological Competence and Written Proficiency. In G.M. Blue and R. Mitchell (eds.), Language and Education. Oxford: Oxford University Press.

Drysdale, P. (1995). The role of examples in a Lerner's dictionary. In A.P. Cowie (ed.,). The Dictionary and the Language Learner. Tübingen: Niemyer.

Hartmann, R.R.K. (1991). What is the Use of Learners' Dictionaries? Institute of Language in Education Journal. 8. 7383.

Hartmann, R.R.K. (2002). Thematic Network Project in the Area of Languages. Subproject 9: Dictionaries. Exeter.

Hartmann, R.R.K. 2003). Lexicography with particular reference to English learners' dictionaries. Language Teaching. 25. 151-59.

Hartmann, R.R.K. (1994). The Learners Dictionary: Unilingual or Interlingual? In L. Flowerdew and K.K. Tong (ed.,) Entering Text. Hong Kong: The Hong Kong University.

Hartmann, R.R.K. (1998). Dictionaries and their Users. Exeter: University of Exeter.

Hornby, A.S. (1965). Some Problems of Lexicography. English Language Teaching, 3, 104-110.

Hornby, A.S. (2000). Oxford Advanced Learners Dictionary ( $7^{\text {th }}$ ed.). Oxford: Oxford University Press.

Hupka, W. (1995). Word and Picture: Illustrations in Dictionaries and Encyclopedias. Tübingen: Niemeyer.

Hulmert, J. (1978). Dictionaries: British and American. London: Deutsch.

IIlson, R. (1985). (ed.,) Dictionaries, Lexicography and Language Learning. Oxford: Pergamon.

Jackson, H. (1988). Words and their Meanings. London: Longman.

Kiefer, B. (1984). Methods of ordering senses within entries. In Hartmann (ed.). (1984): 101-108.

Landau, S.I. (1989). Dictionaries: The Art and Craft of Lexicography. New York: C. Scribner and Sons.

Lyons, J. (2001). Language and Linguistics. Cambridge: Cambridge University Press.

Makiel, V. (2000). Etymological information: can it help students? ELT Journal, 37, 76-82.

Nesi, H. \& Meara, P. (1994). Patterns of misinterpretation in the productive use of EFL dictionary definitions. System, 22(1),1,15.

Nesi, H. (2000). The Specification of Dictionary Reference Skills in Higher Education. In R. Hartmann (ed.).Dictionaries in Language Learning: Recommendations, national Reports and Thematic Reports, TNP Subproject: Dictionaries. Berlin.

O'Malley, J.M., \& Chamot, A.U. (1990). Learning strategies in second language acquisition. Cambridge: Cambridge University Press.

Oxford, Rebecca. Language Learning Strategies: Update http://www.cal.org/resources/digest/oxford01.html. Retrieved April 2013.

Scholfield, P. (2002). Why Shouldn't Monolingual Dictionaries be as Easy to Use as Bilingual Ones? [Retrieved January 17,2010, from httpi/www .logman.coml dirtionaaies/tearherr/articles/p-rcholfield- 02. htndj.

Sinclair, J. (ed.,). (1987). Looking-Up. An Account of the COBUILD Project in Lexical Computing and the Development of Collins Co-Build English Language Dictionary. London: Harper Collins.

Stein, G. (2002). Better Words: Evaluation of EFL Dictionaries. Exeter: Exeter University Press.

Tono, Y. (1998). Assessment of the EFL Learner's Dictionary Using Skills. JACET Bulletin 19: 103-26.

Underhill, A. (1989). Using Your Dictionary. Oxford: Oxford University Press.

Whitcut, J. (1995). The Training of Dictionary Users. Manchester ELT Monograph.

Wright, J. (2001). Dictionaries, Resource Books for Teachers, Oxford University Press, Oxford.

Zgusta, L. (1971). Manual of Lexicography. The Hague: Mouton.

Zahner, G. (2004) Lexical resources in CALL. Computer Education 23. 172.75. 